\title{
Reliable Ohmic Contact Properties for Ni/Hydrogen-Terminated Diamond at Annealing Temperature up to $900^{\circ} \mathrm{C}$
}

\author{
Xiaolu Yuan ${ }^{1,2}{ }^{(D}$, Jiangwei Liu ${ }^{2, *} \mathbb{D}$, Jinlong Liu ${ }^{1}$, Junjun Wei ${ }^{1}$, Bo Da $^{3}$, Chengming $\mathrm{Li}^{1, *}$ and Yasuo Koide ${ }^{2}$ \\ 1 Institute for Advanced Materials and Technology, University of Science and Technology Beijing, \\ Beijing 100083, China; luzi@semi.ac.cn (X.Y.); liujinlong@ustb.edu.cn (J.L.); weijj@ustb.edu.cn (J.W.) \\ 2 Research Center for Functional Materials, National Institute for Materials Science (NIMS), 1-1 Namiki, \\ Tsukuba, Ibaraki 305-0044, Japan; koide.yasuo@nims.go.jp \\ 3 Research and Services Division of Materials Data and Integrated System, NIMS, 1-1 Namiki, Tsukuba, \\ Ibaraki 305-0044, Japan; DA.Bo@nims.go.jp \\ * Correspondence: liu.jiangwei@nims.go.jp (J.L.); chengmli@mater.ustb.edu.cn (C.L.)
}

Citation: Yuan, X.; Liu, J.; Liu, J.; Wei, J.; Da, B.; Li, C.; Koide, Y. Reliable Ohmic Contact Properties for $\mathrm{Ni} /$ Hydrogen-Terminated Diamond at Annealing Temperature up to $900^{\circ} \mathrm{C}$. Coatings 2021, 11,470 . https://doi.org/10.3390/coatings 11040470

Academic Editor: Aomar Hadjadj

Received: 23 March 2021

Accepted: 13 April 2021

Published: 17 April 2021

Publisher's Note: MDPI stays neutral with regard to jurisdictional claims in published maps and institutional affiliations.

Copyright: (c) 2021 by the authors. Licensee MDPI, Basel, Switzerland. This article is an open access article distributed under the terms and conditions of the Creative Commons Attribution (CC BY) license (https:/ / creativecommons.org/licenses/by/ $4.0 /)$.

\begin{abstract}
Ohmic contact with high thermal stability is essential to promote hydrogen-terminated diamond (H-diamond) electronic devices for high-temperature applications. Here, the ohmic contact characteristics of $\mathrm{Ni} / \mathrm{H}$-diamond at annealing temperatures up to $900{ }^{\circ} \mathrm{C}$ are investigated. The measured current-voltage curves and deduced specific contact resistance $\left(\rho_{C}\right)$ are used to evaluate the quality of the contact properties. Schottky contacts are formed for the as-received and $300{ }^{\circ} \mathrm{C}$ annealed $\mathrm{Ni} / \mathrm{H}$-diamonds. When the annealing temperature is increased to $500{ }^{\circ} \mathrm{C}$, the ohmic contact properties are formed with the $\rho_{C}$ of $1.5 \times 10^{-3} \Omega \cdot \mathrm{cm}^{2}$ for the Ni/H-diamond. As the annealing temperature rises to $900{ }^{\circ} \mathrm{C}$, the $\rho_{C}$ is determined to be as low as $6.0 \times 10^{-5} \Omega \cdot \mathrm{cm}^{2}$. It is believed that the formation of $\mathrm{Ni}$-related carbides at the $\mathrm{Ni} / \mathrm{H}$-diamond interface promotes the decrease in $\rho_{\mathrm{C}}$. The $\mathrm{Ni}$ metal is extremely promising to be used as the ohmic contact electrode for the H-diamond-based electronic devices at temperature up to $900{ }^{\circ} \mathrm{C}$.
\end{abstract}

Keywords: hydrogen-terminated diamond (H-diamond); ohmic contact; Ni; specific contact resistance; high-temperature

\section{Introduction}

Diamond, with many remarkable intrinsic properties, possesses vast prospect applications for high-power, high-frequency, and high-temperature electronics [1-3]. It exhibits an ultrawide energy bandgap $(5.5 \mathrm{eV})$, high carrier mobilities $\left(4500\right.$ and $3800 \mathrm{~cm}^{2} \cdot \mathrm{V}^{-1} \cdot \mathrm{s}^{-1}$ for electrons and holes, respectively), large breakdown field strength $\left(10 \mathrm{MV} \cdot \mathrm{cm}^{-1}\right)$, and the highest thermal conductivity $\left(22 \mathrm{~W} \mathrm{~cm}^{-1} \cdot \mathrm{K}^{-1}\right)$ [4]. Compared with boron-doped diamond, hydrogen-terminated diamond (H-diamond) shows outstanding p-type surface conductivity with a hole carrier concentration up to $\sim 10^{14} \mathrm{~cm}^{-2}[5,6]$. Recently, H-diamond-based field-effect transistors have achieved excellent device performances, such as a high breakdown voltage $(2000 \mathrm{~V})$, a high-output current density $\left(1.3 \mathrm{~A} \cdot \mathrm{mm}^{-1}\right)$, and a high-output power density $\left(3.8 \mathrm{~W} \cdot \mathrm{mm}^{-1}\right)[1,7,8]$. Meanwhile, the passivation layer protection for the $\mathrm{H}$-diamond surface improves the conductive stability of $\mathrm{H}$-diamond-based electronic devices, even at temperatures as high as $500{ }^{\circ} \mathrm{C}$ [9-11]. The re-hydrogenation process enables the H-diamond surface damaged during annealing to regain good conductivity [12].

In order to further promote H-diamond-based electronic devices to be operated well at high temperatures, thermal-stable ohmic contact is essential. Until now, different kinds of metals are used for ohmic contacts on the H-diamond, such as, $\mathrm{Au}, \mathrm{Pd}, \mathrm{Pt}, \mathrm{W}, \mathrm{Ti} / \mathrm{Au}$, $\mathrm{Pt} / \mathrm{Au}, \mathrm{Pd} / \mathrm{Ti} / \mathrm{Au}, \mathrm{Ti} / \mathrm{Ni} / \mathrm{Au}$, etc. [12-15] They show good ohmic contact properties and high thermal stability, with annealing temperatures up to $700{ }^{\circ} \mathrm{C}$. On the other hand, the $\mathrm{Ni}$ metal tends to form Schottky contact with the H-diamond at an annealing temperature lower than $100{ }^{\circ} \mathrm{C}$ [16]. However, $\mathrm{Ni}$, as a carbophilic element, is prone to react with carbon 
at an elevated temperature [17]. The solid-solution reaction makes the Ni-related carbides formed at the $\mathrm{Ni} / \mathrm{H}$-diamond interface, which would possibly contribute to the formation of ohmic contact.

Here, ohmic contact characteristics of $\mathrm{Ni} / \mathrm{H}$-diamond at annealing temperatures up to $900{ }^{\circ} \mathrm{C}$ are investigated. The measured current-voltage curves and deduced specific contact resistance $\left(\rho_{C}\right)$ are used to evaluate the quality of the contact properties.

\section{Experimental}

\subsection{Preparation of H-Diamond Epitaxial Layer}

An Ib-type (100) facet single-crystalline diamond was boiled in mixed $\mathrm{H}_{2} \mathrm{SO}_{4}$ and $\mathrm{HNO}_{3}$ solutions at $300^{\circ} \mathrm{C}$ for $3 \mathrm{~h}$. Then, it was ultrasonically cleaned using acetone, ethanol, and deionized water sequentially. A 150-nm-thick H-diamond epitaxial layer was grown using a microwave plasma-enhanced chemical vapor deposition system. The $\mathrm{CH}_{4}$ flow rate, $\mathrm{H}_{2}$ flow rate, chamber pressure, and deposition temperature were $0.5 \mathrm{sccm}, 500 \mathrm{sccm}$, 80 Torr, and $900-940{ }^{\circ} \mathrm{C}$, respectively.

\subsection{Formation of Transmission Line Model (TLM) Patterns for Ni on the H-Diamond}

The H-diamond was sequentially coated with LOR5A and AZ5214E positive photoresists using a spin-coater with a rotation rate and time of $7000 \mathrm{rpm}$ and $1 \mathrm{~s}$, respectively. After exposing using a mask-less lithography system with a dose energy of $250 \mathrm{~mJ} \cdot \mathrm{cm}^{-2}$, the sample was developed in a $2.38 \%$ tetramethylammonium hydroxide solution for $90 \mathrm{~s}$. The Ti metal used as key-patterns was deposited on the H-diamond by a J-sputter system in an Ar atmosphere in order to align the positions of the mesa structure and contact metals. The mesa structure was formed using a capacitively coupled plasma reactive-ion etching system. The plasma power, $\mathrm{O}_{2}$ flow rate, and etching time were $50 \mathrm{~W}, 100 \mathrm{sccm}$, and $90 \mathrm{~s}$, respectively. The five-group TLM electrode patterns were completed using the lithography procedures. The $\mathrm{Ni}$, with a thickness of $100 \mathrm{~nm}$, was grown on the $\mathrm{H}$-diamond for ohmic contact via an e-beam evaporation system under a $\sim 10^{-5} \mathrm{~Pa}$ vacuum condition.

\subsection{Annealing Process and Current-Voltage Measurements}

The annealing process was performed using a rapid thermal annealing system in an Ar atmosphere. The annealing temperatures were 300, 500, 700, and $900{ }^{\circ} \mathrm{C}$ with an annealing time of $10 \mathrm{~min}$ for each temperature. After annealing, the sample was exposed to air for more than $10 \mathrm{~h}$ in order to promote the formation of a negatively adsorbed layer on the surface of the $\mathrm{H}$-diamond, and to regain good surface conductivity. The calculations of $\rho_{\mathrm{C}}$ for the $\mathrm{Ni} / \mathrm{H}$-diamond with the TLM patterns can be referred to in the previous reports $[18,19]$. The electrical properties of $\mathrm{Ni} / \mathrm{H}$-diamond contacts were characterized by a room-temperature probe system.

\section{Results and Discussion}

Figure 1 shows the surface morphology of five-group TLM patterns of Ni on the $\mathrm{H}$-diamond epitaxial layer before annealing. The length and width of each electrode are the same as $100 \mu \mathrm{m}$. All the Ni metals were stable to be formed on the H-diamond. The five groups of TLM patterns were used to characterize current-voltage curves for the $\mathrm{Ni} / \mathrm{H}$-diamonds of as-received, $300{ }^{\circ} \mathrm{C}$-annealed, $500{ }^{\circ} \mathrm{C}$-annealed, $700{ }^{\circ} \mathrm{C}$-annealed, and $900{ }^{\circ} \mathrm{C}$-annealed, respectively. The interspace $(d)$ values from left to right in Figure 1, between the two adjacent electrodes for the five-group TLM patterns, are in the ranges of 7.9-9.1 $\mu \mathrm{m}, 13.5-13.9 \mu \mathrm{m}, 18.0-18.8 \mu \mathrm{m}, 23.1-23.9 \mu \mathrm{m}$ and $28.2-29.1 \mu \mathrm{m}$, respectively.

Figure 2 shows current-voltage characteristics of (a) the as-received and (b) the $300{ }^{\circ} \mathrm{C}$ -annealed $\mathrm{Ni} / \mathrm{H}$-diamond contacts, respectively. The applied voltage is in the range of $-1.0-1.0 \mathrm{~V}$. For the as-received $\mathrm{Ni} / \mathrm{H}$-diamond contact, the output currents are in the order of $10^{-7} \mathrm{~A}$ (Figure 2a). All the curves show non-linear characteristics, indicating the Schottky contacts. After annealing at $300{ }^{\circ} \mathrm{C}$ for $10 \mathrm{~min}$, as shown in Figure $2 \mathrm{~b}$, the output currents of the $\mathrm{Ni} / \mathrm{H}$-diamond increase to the order of $10^{-4} \mathrm{~A}$. The annealing process improves 
the contact properties of the Ni/H-diamond. However, all the curves still show nonlinear characteristics. Therefore, even after annealing at $300^{\circ} \mathrm{C}$, the $\mathrm{Ni} / \mathrm{H}$-diamond still operates with Schottky contacts, which is consistent with the results obtained from the other report [20]. The presence of a chemisorbed species on the H-diamond surface possibly results in the formation of Schottky contact. However, the annealing process can improve the contact interface of the $\mathrm{Ni} / \mathrm{H}$-diamond, thereby promoting the current flow.

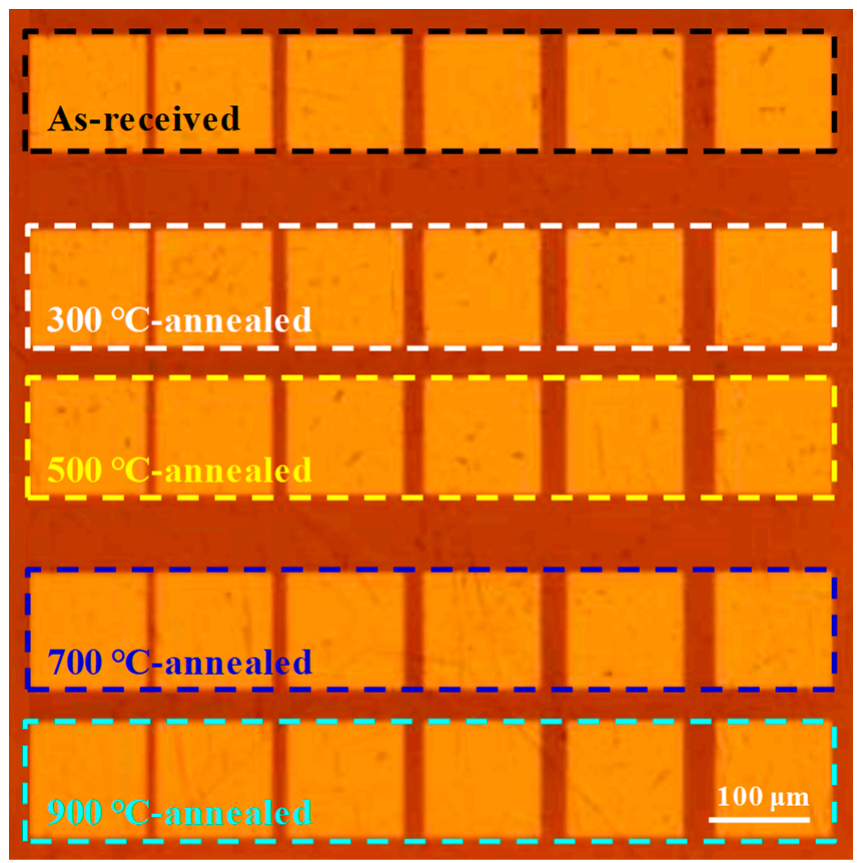

Figure 1. Surface morphology of the five-group transmission line model (TLM) patterns of Ni on the hydrogen-terminated diamond (H-diamond) epitaxial layer before annealing. They were used to characterize current-voltage curves for the $\mathrm{Ni} / \mathrm{H}$-diamonds of as-received, $300{ }^{\circ} \mathrm{C}$-annealed, $500{ }^{\circ} \mathrm{C}$-annealed, $700{ }^{\circ} \mathrm{C}$-annealed, and $900{ }^{\circ} \mathrm{C}$-annealed, respectively.

(a) As-received

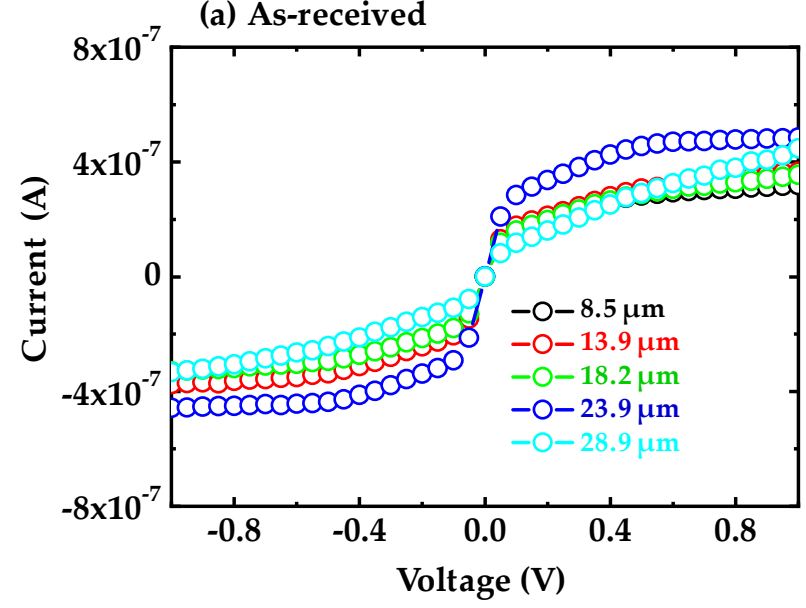

(b) $300{ }^{\circ} \mathrm{C}$-annealed

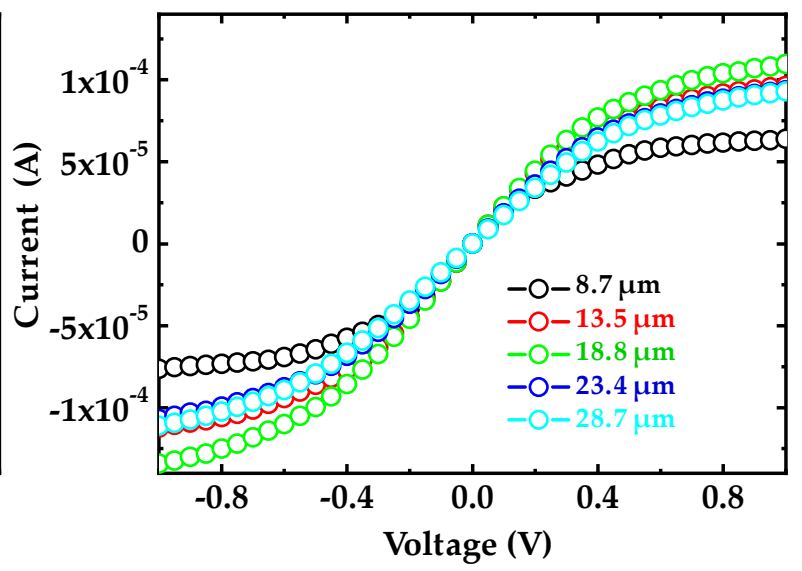

Figure 2. Current-voltage characteristics of (a) the as-received and (b) the $300{ }^{\circ} \mathrm{C}$-annealed $\mathrm{Ni} / \mathrm{H}$-diamond contacts, respectively.

Figure 3a shows the current-voltage characteristics of the Ni/H-diamond after annealing at $500{ }^{\circ} \mathrm{C}$. All the current-voltage curves have linear characteristics, which implies good ohmic contacts for the $\mathrm{Ni} / \mathrm{H}$-diamond. For two adjacent electrodes in which $d=8.7 \mu \mathrm{m}$, the output currents are $2.0 \times 10^{-4} \mathrm{~A}$ at $\pm 1.0 \mathrm{~V}$. The total resistance $\left(R_{\mathrm{T}}\right)$ for the $500{ }^{\circ} \mathrm{C}$ - 
annealed Ni/H-diamond can be calculated to be $4.9 \times 10^{3} \Omega(d=8.7 \mu \mathrm{m})$. Based on the current-voltage characteristics for other adjacent electrodes (Figure 3a), the $R_{\mathrm{T}}$ for the $\mathrm{Ni} / \mathrm{H}$-diamond with other $d$ values is also calculated and summarized in Figure $3 \mathrm{~b}$. There are the following relationships for the $R_{\mathrm{T}}$ and $\rho_{\mathrm{C}}$ with the $\mathrm{Ni} / \mathrm{H}$-diamond contact resistance $\left(R_{\mathrm{C}}\right), \mathrm{H}$-diamond surface sheet resistance $\left(R_{\mathrm{S}}\right)$, electrode transfer length $\left(L_{\mathrm{T}}\right)$, and electrode width $(W)[18]$ :

$$
\begin{gathered}
R_{\mathrm{T}}=2 R_{\mathrm{C}}+\frac{R_{\mathrm{s}}}{W} d \\
\rho_{\mathrm{C}}=R_{\mathrm{C}} \times L_{\mathrm{T}} \times W
\end{gathered}
$$

(a) $500{ }^{\circ} \mathrm{C}$-annealed

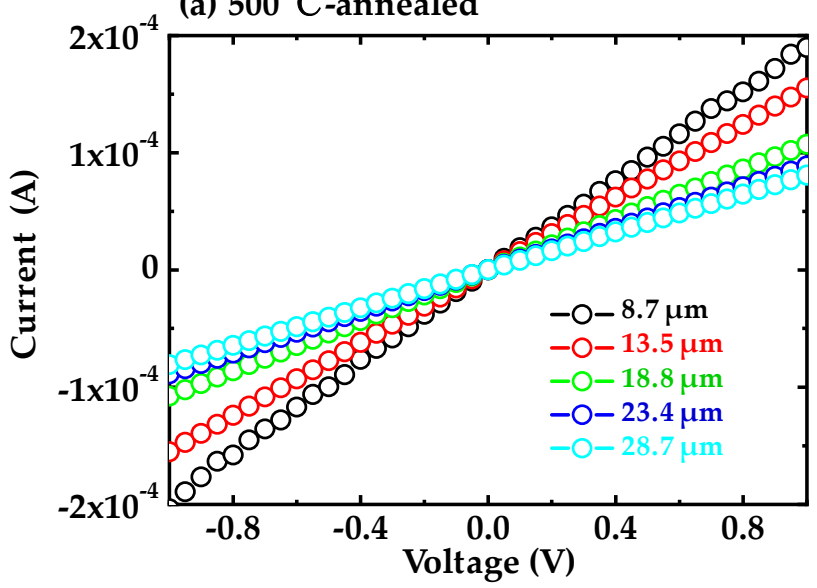

(c) $700{ }^{\circ} \mathrm{C}$-annealed

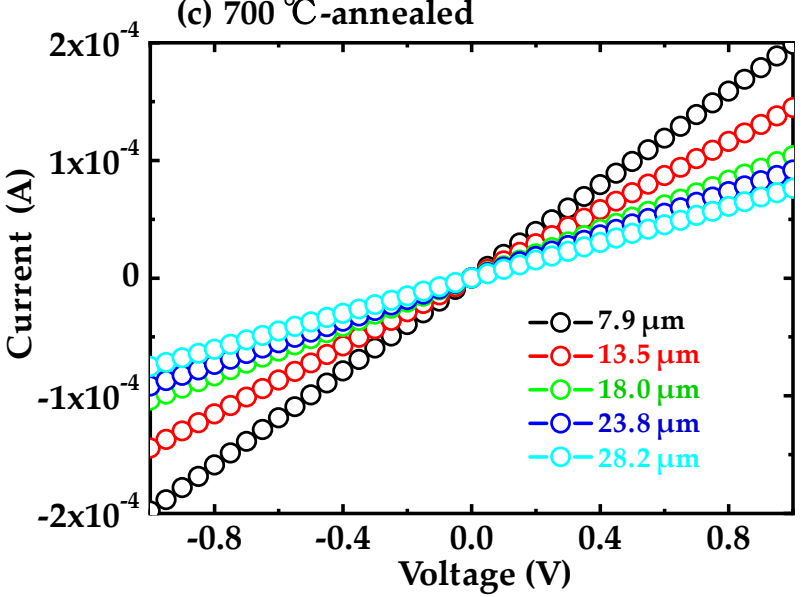

\section{(b) $500{ }^{\circ} \mathrm{C}$-annealed}

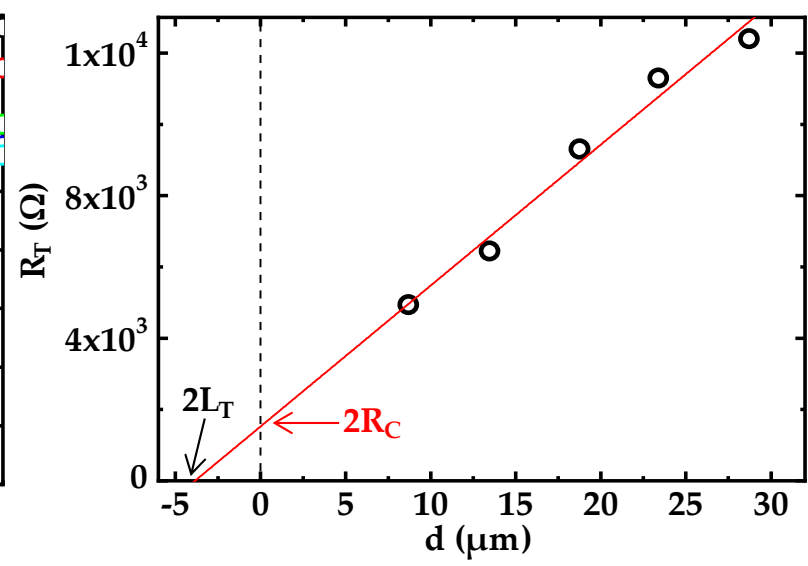

(d) $700{ }^{\circ} \mathrm{C}$-annealed

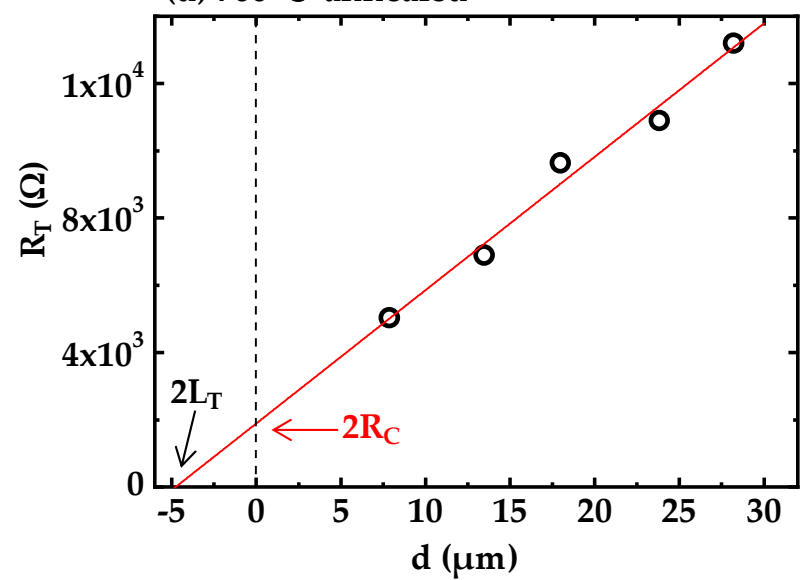

Figure 3. (a,c) Current-voltage characteristics of the $500{ }^{\circ} \mathrm{C}$-annealed and $700{ }^{\circ} \mathrm{C}$-annealed $\mathrm{Ni} / \mathrm{H}$-diamonds, respectively. (b,d) $R_{T}$ as functions of $d$ for the $500{ }^{\circ} \mathrm{C}$-annealed and $700{ }^{\circ} \mathrm{C}$-annealed $\mathrm{Ni} / \mathrm{H}$-diamonds, respectively.

By fitting the spots in Figure $3 \mathrm{~b}$, the $R_{\mathrm{S}} / W$ (the slope of fitting line) are determined to be $4.0 \times 10^{2} \Omega \cdot \mu \mathrm{m}^{-1}$ with an $R_{\mathrm{S}}$ of $40 \mathrm{k} \Omega$. The $2 R_{\mathrm{C}}$ (the intercept of the $y$-axis) and $2 L_{\mathrm{T}}$ (the intercept of the $x$-axis) are deduced to be $1.5 \times 10^{3} \Omega$ and $3.9 \mu \mathrm{m}$, respectively. Based on Equation (2), the $\rho_{\mathrm{C}}$ for the $500{ }^{\circ} \mathrm{C}$-annealed $\mathrm{Ni} / \mathrm{H}$-diamond can be calculated to be $1.5 \times 10^{-3} \Omega \cdot \mathrm{cm}^{2}$.

When the annealing temperature is increased to $700{ }^{\circ} \mathrm{C}$, the output current maxima are the same level as those of the $500^{\circ} \mathrm{C}$-annealed Ni/H-diamond (Figure 3c). The linear characteristics for all the current-voltage curves are observed, indicating the good ohmic properties for the $700{ }^{\circ} \mathrm{C}$-annealed $\mathrm{Ni} / \mathrm{H}$-diamond. Figure $3 \mathrm{~d}$ shows the $R_{\mathrm{T}}$ as a function of $d$ for the $\mathrm{Ni} / \mathrm{H}$-diamond after annealing at $700{ }^{\circ} \mathrm{C}$. By fitting the spots, the $R_{S} / W, 2 R_{C}$, and $2 L_{\mathrm{T}}$ are obtained to be $4.0 \times 10^{2} \Omega \cdot \mu \mathrm{m}^{-1}, 1.9 \times 10^{3} \Omega$, and $4.8 \mu \mathrm{m}$, respectively. The $R_{\mathrm{S}}$ and $\rho_{\mathrm{C}}$ for the $\mathrm{Ni} / \mathrm{H}$-diamond after annealing at $700{ }^{\circ} \mathrm{C}$ are calculated to be 
$40 \mathrm{k} \Omega$ and $2.3 \times 10^{-3} \Omega \cdot \mathrm{cm}^{2}$, respectively, which are close to those of the $500{ }^{\circ} \mathrm{C}$-annealed $\mathrm{Ni} / \mathrm{H}$-diamond.

Figure $4 \mathrm{a}$ shows the current-voltage curves of the $\mathrm{Ni} / \mathrm{H}$-diamond after annealing at $900^{\circ} \mathrm{C}$. All the curves have good linear relationships. Therefore, the ohmic contacts of the $\mathrm{Ni} / \mathrm{H}$-diamond possess good thermal stability even after annealing at temperatures as high as $900{ }^{\circ} \mathrm{C}$ for $10 \mathrm{~min}$, which is comparable with those of the Ni/SiC contacts [21,22].

(a) $900{ }^{\circ} \mathrm{C}$-annealed

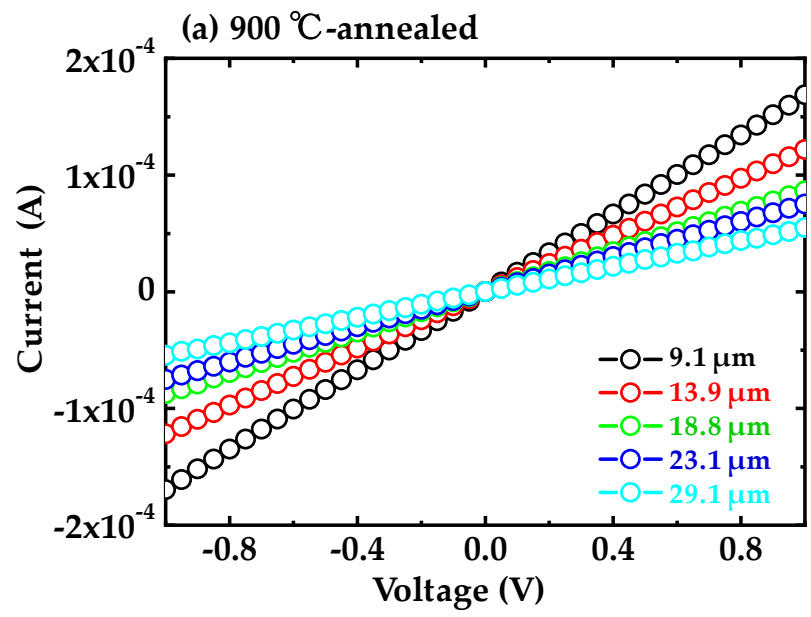

(b) $900{ }^{\circ} \mathrm{C}$-annealed

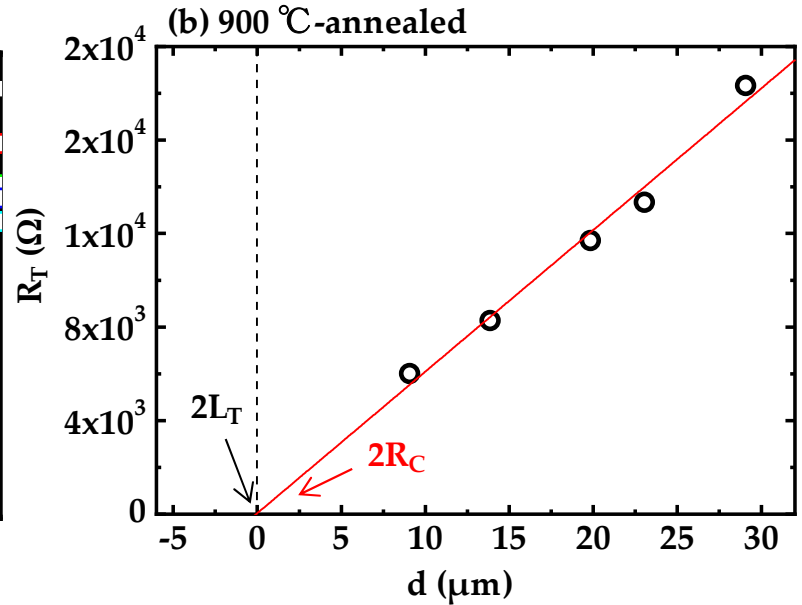

Figure 4. (a) Current-voltage characteristics and (b) total resistance $\left(R_{\mathrm{T}}\right)$ as functions of $d$ for the $900{ }^{\circ} \mathrm{C}$-annealed Ni/Hdiamond.

Comparing with the output currents of the $500{ }^{\circ} \mathrm{C}$-annealed and $700{ }^{\circ} \mathrm{C}$-annealed $\mathrm{Ni} / \mathrm{H}$-diamonds at $\pm 1.0 \mathrm{~V}$, those for the $900^{\circ} \mathrm{C}$-annealed one decreased slightly. Figure $4 \mathrm{~b}$ shows the corresponding $R_{\mathrm{T}}$ as a function of $d$ for the $\mathrm{Ni} / \mathrm{H}$-diamond after annealing at $900{ }^{\circ} \mathrm{C}$. The $R_{\mathrm{S}} / W, 2 R_{\mathrm{C}}$, and $L_{\mathrm{T}}$ are deduced to be $6.1 \times 10^{2} \Omega \cdot \mu \mathrm{m}^{-1}, 37.9 \Omega$, and $0.1 \mu \mathrm{m}$, respectively. The $R_{\mathrm{S}}$ and $\rho_{\mathrm{C}}$ are calculated to be $60.6 \mathrm{k} \Omega$ and $6.0 \times 10^{-5} \Omega \cdot \mathrm{cm}^{2}$. The $\rho_{C}$ is comparable with other metals on the H-diamond [23,24]. The thermal-stable $\mathrm{Ni} / \mathrm{H}$-diamond ohmic contacts exhibit advantages for the high-temperature application of $\mathrm{H}$-diamond-based devices.

Figure $5 \mathrm{a}, \mathrm{b}$ compare the $R_{\mathrm{C}}, R_{\mathrm{S}}$ and $\rho_{\mathrm{C}}$ of the $\mathrm{Ni} / \mathrm{H}$-diamonds after annealing at 500 , 700 , and $900{ }^{\circ} \mathrm{C}$, respectively. After annealing at 500 and $700{ }^{\circ} \mathrm{C}$, the $R_{\mathrm{C}}$ and $R_{\mathrm{S}}$ values of the $\mathrm{Ni} / \mathrm{H}$-diamonds show no obvious changes. After annealing at $900{ }^{\circ} \mathrm{C}$, however, the $R_{\mathrm{C}}$ decreases to $19.0 \Omega$, while the $R_{\mathrm{S}}$ increases to $60.6 \mathrm{k} \Omega$. The increased $R_{\mathrm{S}}$ is possibly attributed to the damage of $\mathrm{C}-\mathrm{H}$ bonds or the desorbed absorption layer on the $\mathrm{H}$-diamond surface after multiplied high-temperature treatments [5]. The decrease in $R_{C}$ may be due to the carbon phase transition at the interface between $\mathrm{Ni}$ and $\mathrm{H}$-diamond at high temperatures $[24,25]$. Under the catalysis of nickel, diamond is prone to transform into the graphite phase or form carbide related with $\mathrm{Ni}$, which greatly increases the electrical conductivity, thereby greatly reducing the contact resistance at the interface.

In order to confirm the interface reaction between $\mathrm{Ni}$ and $\mathrm{H}$-diamond after annealing, transmission electron microscope (TEM) (Figure 6a) and energy dispersive spectrometer (EDS) (Figure $6 \mathrm{~b}$ ) measurements for the $\mathrm{Ni} / \mathrm{H}$-diamond after annealing were performed. The interface for the $\mathrm{Ni} / \mathrm{H}$-diamond is ambiguous and curved after annealing. The EDS result shows a great number of carbon atoms from diamond dissolved into the Ni lattice. Therefore, the carbides related with $\mathrm{Ni}$ for the $\mathrm{Ni} / \mathrm{H}$-diamond are formed at the interface, which leads to a lower $\rho_{C}$. 
(a)

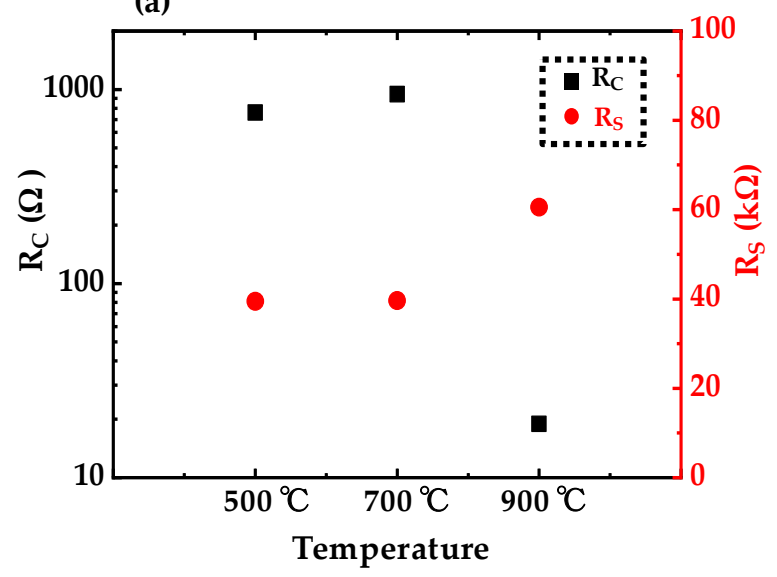

(b)

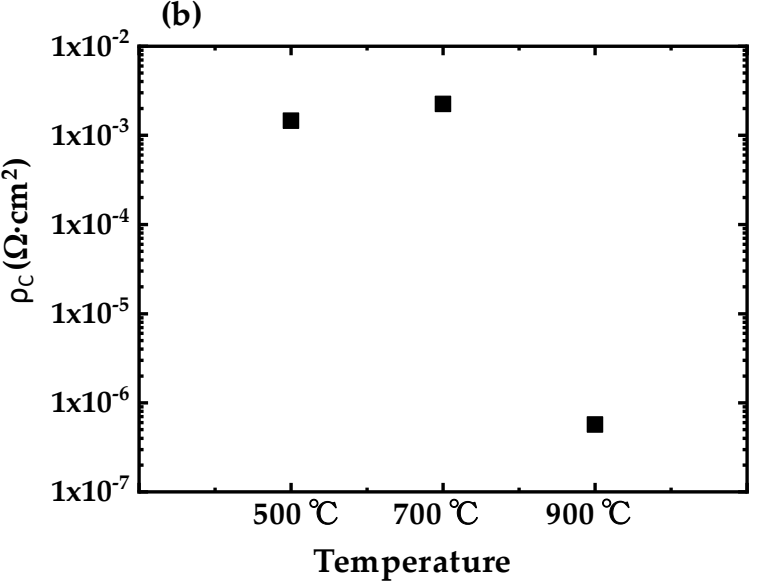

Figure 5. Summary of $(\mathbf{a})$ the contact resistance $\left(R_{\mathrm{C}}\right)$ and surface sheet resistance $\left(R_{\mathrm{S}}\right)$, and $(\mathbf{b})$ the deduced specific contact resistance $\left(\rho_{\mathrm{C}}\right)$ for the $\mathrm{Ni} / \mathrm{H}$-diamond after annealing at 500,700 , and $900{ }^{\circ} \mathrm{C}$, respectively.

(a)

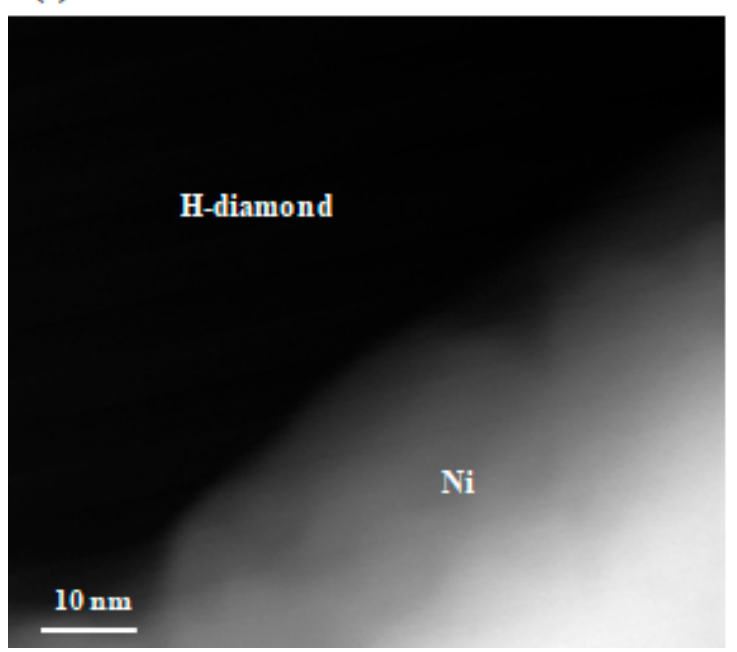

(b)

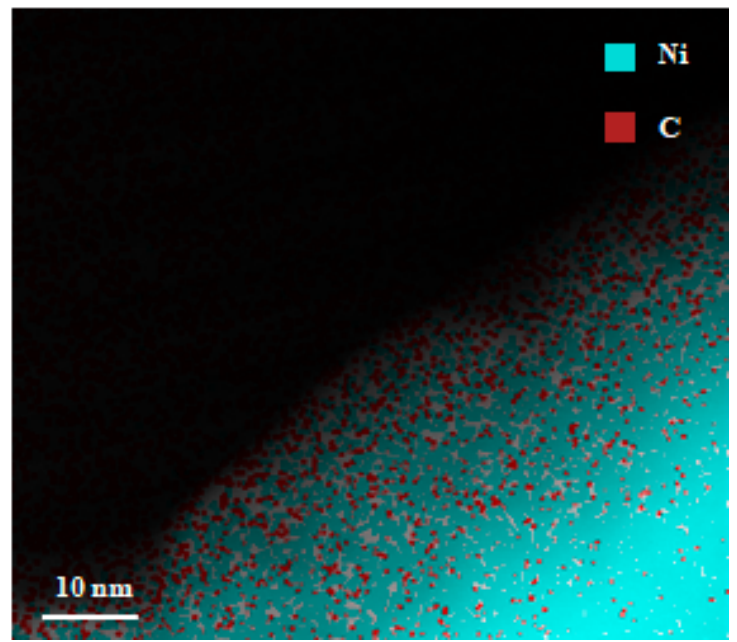

Figure 6. (a) Transmission electron microscope (TEM) and (b) energy dispersive spectrometer (EDS) images for the interface of the $\mathrm{Ni} / \mathrm{H}$-diamond after annealing at $900^{\circ} \mathrm{C}$, respectively.

\section{Conclusions}

In this study, ohmic contact characteristics of the $\mathrm{Ni} / \mathrm{H}$-diamond at annealing temperatures up to $900{ }^{\circ} \mathrm{C}$ were investigated. Schottky contacts were formed for the as-received and the $300{ }^{\circ} \mathrm{C}$-annealed $\mathrm{Ni} / \mathrm{H}$-diamonds. When the annealing temperatures were increased to $500{ }^{\circ} \mathrm{C}$, ohmic contacts were formed with the $\rho_{\mathrm{C}}$ of $1.5 \times 10^{-3} \Omega \cdot \mathrm{cm}^{2}$ for the $\mathrm{Ni} / \mathrm{H}$-diamond. For the $700{ }^{\circ} \mathrm{C}$-annealed $\mathrm{Ni} / \mathrm{H}$-diamond, the $\rho_{\mathrm{C}}$ was the same level as that of the $500{ }^{\circ} \mathrm{C}$-annealed one. As the annealing temperature rose to $900{ }^{\circ} \mathrm{C}$, the specific contact resistance was as low as $6.0 \times 10^{-5} \Omega \cdot \mathrm{cm}^{2}$. It is believed that the formation of Ni-related carbides at the $\mathrm{Ni} / \mathrm{H}$-diamond interface promoted the decrease in specific contact resistance. Therefore, the thermal-stable $\mathrm{Ni} / \mathrm{H}$-diamond ohmic contacts exhibited advantages for the high-temperature application of $\mathrm{H}$-diamond-based devices.

Author Contributions: Conceptualization, J.L. (Jiangwei Liu); methodology, X.Y. and J.L. (Jiangwei Liu); validation, X.Y., J.L. (Jinlong Liu), and J.W.; formal analysis, X.Y. and B.D.; investigation, X.Y. and J.L. (Jiangwei Liu); resources, J.L. (Jiangwei Liu), C.L. and Y.K.; data curation, X.Y. and J.L. (Jiangwei Liu); writing — original draft preparation, X.Y.; writing—review and editing, J.L. (Jiangwei Liu); supervision, J.L. (Jiangwei Liu) and C.L.; funding acquisition, J.L. (Jiangwei Liu) Y.K., and C.L. All authors have read and agreed to the published version of the manuscript. 
Funding: This work is supported partly by the Leading Initiative for Excellent Young Researchers Program Project, the KAKENHI Project under grant numbers of JP20H00313 and JP16H06419, and the NIMS Nanofabrication Platform of the Nanotechnology Platform Project sponsored by the Ministry of Education, Culture, Sports, and Technology, Japan. It is supported partly by the National Key Research and Development Program of China (No. 2016YFE0133200).

Institutional Review Board Statement: Not applicable.

Informed Consent Statement: Not applicable.

Data Availability Statement: The data presented in this study are available on request from the corresponding author.

Conflicts of Interest: The authors declare no conflict of interest.

\section{References}

1. Imanishi, S.; Horikawa, K.; Oi, N.; Okubo, S.; Kageura, T.; Hiraiwa, A.; Kawarada, H. 3.8W/mm RF power density for ALD $\mathrm{Al}_{2} \mathrm{O}_{3}$-based two-dimensional hole gas diamond mosfet operating at saturation velocity. IEEE Electron. Device Lett. 2019, 40, 279-282. [CrossRef]

2. Anniyev, T.; Vasilyev, M.; Khabashesku, V.; Inanc, F. High-temperature diamond detector for neutron generator output monitoring in well logging applications. IEEE Trans. Nucl. Sci. 2020, 67, 1885-1892. [CrossRef]

3. Yu, X.X.; Zhou, J.J.; Qi, C.J.; Cao, Z.Y.; Kong, Y.C.; Chen, T.S. A High frequency hydrogen-terminated diamond MISFET with $\mathrm{f}_{\mathrm{T}} / \mathrm{f}_{\max }$ of 70/80 GHz. IEEE Electron. Device Lett. 2018, 39, 1373-1376. [CrossRef]

4. Wort, C.J.H.; Balmer, R.S. Diamond as an electronic material. Mater. Today 2008, 11, 22-28. [CrossRef]

5. Williams, O.A.; Jackman, R.B. Surface conductivity on hydrogen terminated diamond. Semicond. Sci. Technol. 2003, 18, S34-S40. [CrossRef]

6. Kubovic, M.; Kasu, M. Improvement of hydrogen-terminated diamond field effect transistors in nitrogen dioxide atmosphere. Appl. Phys. Express 2009, 2, 086502. [CrossRef]

7. Hirama, K.; Sato, H.; Harada, Y.; Yamamoto, H.; Kasu, M. Diamond field-effect transistors with 1.3 A/mm drain current density by $\mathrm{Al}_{2} \mathrm{O}_{3}$ passivation Layer. Jpn. J. Appl. Phys. 2012, 51, 090112.

8. Kitabayashi, Y.; Kudo, T.; Tsuboi, H.; Yamada, T.; Xu, D.; Shibata, M.; Matsumura, D.; Hayashi, Y.; Syamsul, M.; Inaba, M.; et al. Normally-off C-H diamond MOSFETs with partial C-O channel achieving 2-kV breakdown voltage. IEEE Electron. Device Lett. 2017, 38, 363-366. [CrossRef]

9. Kawarada, H.; Tsuboi, H.; Naruo, T.; Yamada, T.; Xu, D.; Daicho, A.; Saito, T.; Hiraiwa, A. C-H surface diamond field effect transistors for high temperature $\left(400{ }^{\circ} \mathrm{C}\right)$ and high voltage (500 V) operation. Appl. Phys. Lett. 2014, 105, 013510. [CrossRef]

10. Liu, J.W.; Oosato, H.; Da, B.; Teraji, T.; Kobayashi, A.; Fujioka, H.; Koide, Y. Operations of hydrogenated diamond metal-oxidesemiconductor field-effect transistors after annealing at $500{ }^{\circ} \mathrm{C}$. J. Phys. D Appl. Phys. 2019, 52, 315104. [CrossRef]

11. Ren, Z.Y.; Yuan, G.S.; Zhang, J.F.; Xu, L.; Zhang, J.C.; Chen, W.J.; Hao, Y. Hydrogen-terminated polycrystalline diamond MOSFETs with $\mathrm{Al}_{2} \mathrm{O}_{3}$ passivation layers grown by atomic layer deposition at different temperatures. AIP Adv. 2018, 8, 065026. [CrossRef]

12. Vardi, A.; Tordjman, M.; Kalish, R.; Alamo, J.A.d. Refractory W Ohmic contacts to H-terminated diamond. IEEE Trans. Electron. Devices 2020, 67, 3516-3521. [CrossRef]

13. Xing, K.J.; Tsai, A.; Rubanov, S.; Creedon, D.L.; Yianni, S.A.; Zhang, L.; Hao, W.C.; Zhuang, J.C.; McCallum, J.C.; Pakes, C.I.; et al. Palladium forms Ohmic contact on hydrogen-terminated diamond down to 4 K. Appl. Phys. Lett. 2020, 116, 111601. [CrossRef]

14. Zhang, M.H.; Lin, F.; Wang, W.; Li, F.N.; Wang, Y.F.; Abbasi, H.N.; Zhao, D.; Chen, G.Q.; Wen, F.; Zhang, J.W.; et al. Ohmic contact of $\mathrm{Pt} / \mathrm{Au}$ on hydrogen-terminated single crystal diamond. Coatings 2019, 9, 539. [CrossRef]

15. Umezawa, H.; Ikeda, K.; Kumaresan, R.; Shikata, S. High temperature characteristics of diamond SBDs. Mater. Sci. Forum 2010, 645, 1231-1234. [CrossRef]

16. Tsugawa, K.; Noda, H.; Hirose, K.; Kawarada, H. Schottky barrier heights, carrier density, and negative electron affinity of hydrogen-terminated diamond. Phys. Rev. B 2010, 81, 045303. [CrossRef]

17. Chen, J. Research on Catalytic Etching of Synthetic Diamond by Iron Group Metals. Master's Thesis, Hunan University, Changsha, China, 2015.

18. Reeves, G.K.; Harrison, H.B. Obtaining the specific contact resistance from transmission line model measurements. IEEE Electron. Device Lett. 1982, 3, 111-113. [CrossRef]

19. Berger, H.H. Models for contacts to planar devices. Solid State Electron. 1972, 15, 145-158. [CrossRef]

20. Weide, J.; Nemanich, R.J. Influence of interfacial hydrogen and oxygen on the Schottky barrier height of nickel on (111) and (100) diamond surfaces. Phys. Rev. B 1994, 49, 13629-13637. [CrossRef]

21. Roccaforte, F.; La Via, F.; Raineri, V.; Calcagno, L.; Musumeci, P. Improvement of high temperature stability of nickel contacts on n-type 6H-SiC. Appl. Surf. Sci. 2001, 184, 295-298. [CrossRef]

22. Chang, S.K.; Kim, Y.; Lee, J.; Choi, K. Thermal stability study of Ni-Si silicide films on Ni/4H-SiC contact by in-situ temperaturedependent sheet resistance measurement. Jpn. J. Appl. Phys. 2019, 58, 075503. [CrossRef] 
23. Yuan, X.L.; Liu, J.W.; Shao, S.W.; Liu, J.L.; Wei, J.J.; Da, B.; Li, C.M.; Koide, Y. Thermal stability investigation for Ohmic contact properties of $\mathrm{Pt}, \mathrm{Au}$, and $\mathrm{Pd}$ electrodes on the same hydrogen-terminated diamond. Aip Adv. 2020, 10, 055114. [CrossRef]

24. Zhang, P.F.; Zhang, S.P.; Chen, W.D.; Yan, S.F.; Ma, W.; Wang, H.X. Annealing temperature on contact properties between nickel film and hydrogen-terminated single crystal diamond. Coatings 2020, 10, 876. [CrossRef]

25. Kanada, S.; Nagai, M.; Ito, S.; Matsumoto, T.; Ogura, M.; Takeuchi, D.; Yamasaki, S.; Inokuma, T.; Tokuda, N. Fabrication of graphene on atomically flat diamond (111) surfaces using nickel as a catalyst. Diam. Relat. Mater. 2017, 75, 105-109. [CrossRef] 